\title{
Empathy and big five personality model in medical students and its relationship to gender and specialty preference: a cross- sectional study
}

\author{
Teresa Guilera ${ }^{1,2^{*}}$ (D), Iolanda Batalla $a^{1,2,3}$ (D) Carles Forné $e^{4,5}$ and Jorge Soler-González ${ }^{2,3}$ (B)
}

\begin{abstract}
Background: Given the influence that personality can have on empathy, this study explores the relationship between empathy and personality, using three different measures of empathy, and taking into account gender and specialty preference.

Methods: Cross-sectional study. One hundred and ten medical students completed the Jefferson Scale of Physician Empathy, the Interpersonal Reactivity Index, the Empathy Quotient, and the NEO-FFI Big Five personality model. Multivariable linear regression was performed to assess the association between personality traits and empathy.

Results: Empathy scales showed weak and moderate correlation with personality. The strongest correlations were observed between IRI-Fantasy and Openness, and between IRI-Personal Distress and Neuroticism. Gender and specialty preference can modify this relationship. The extreme groups of Empathy Quotient had significant differences in most personality traits.

Conclusions: This study confirmed that empathy is related to personality. Using three empathy scales allows personalizing the evaluation of different empathy models and its relation with personality. These results can help to design programs to study if some personalized intervention strategies could improve the empathy in medical students.
\end{abstract}

Keywords: Big five model, Empathy, Medical education, Personality, Undergraduate

\section{Background}

Empathy is the ability to identify and understand the thoughts and feelings of others and to respond with appropriate emotions [1]. It is a complex social emotion difficult to conceptualize and measure [2, 3]. Medical empathy has been defined as the predominantly cognitive attribute that involves the ability to understand patients' experiences, concerns, and perspectives, and communicate this understanding with the intention of helping $[4,5]$. There are different empathy scales based on different theoretical models. The JSPE (Jefferson

\footnotetext{
*Correspondence: tguilera37@gmail.com

${ }^{1}$ Psychiatry Service, Santa Maria University Hospital, Rovira Roure Avenue, 44, 25198 Lleida, Spain

${ }^{2}$ Institute for Biomedical research in Lleida Dr. Pifarré Foundation (IRBLleida) Lleida, Spain

Full list of author information is available at the end of the article
}

Scale of Physician Empathy) measures empathy in the context of medical education and patient care [4]. The IRI (Interpersonal Reactivity Index) is a multidimensional approach that permits discrimination between cognitive [IRI-PT (IRI-Perspective Taking) and IRI-FS (IRI-Fantasy Scale)] and affective empathy [IRI-Empathetic Concern (IRI-EC) and IRI-PD (IRI-Personal Distress)] [6, 7]. The EQ (Empathic Quotient) measures cognitive and affective empathy in adults, and is based on the two-dimensional psychological model: empathy and systematization proposed by Baron-Cohen $[1,8]$. There is conflicting evidence about the relationship between empathy in medical students with gender and specialty preference. To date higher empathy scores have been observed in women in JSPE [4, 7, 9-18], in IRI-FS and IRI-PD [7], and in EQ [1]. 
Although other studies report no gender differences [7, 11]. Similarly, some studies of specialty preference show higher empathy scores in medical students with people-oriented versus technology-oriented specialties preference $[2,10,11$, $13,16,19]$, while others do not find a significant difference $[11,14,17,20]$.

Furthermore, personality could be an important variable that could modulate empathy $[7,21]$. Personality is defined as the pattern of thoughts, feelings, attitudes, habits and behaviour of each individual that persists over time in different situations distinguishing one individual from others. The NEO Five-Factor Inventory (NEO-FFI), based on the Big Five personality model [22], allows the evaluation of five main factors: Openness to experience, Conscientiousness, Extraversion, Agreeableness and Neuroticism. Personality is normally considered relatively stable. Personality traits might influence empathetic behaviour towards patients, and might play a role in the selection of students for medicine, or in advice concerning suitability of specialty. The associations between empathy and Big Five personality traits in medical education are still underrepresented in the existing literature [23]. Two studies, which used the JSPE among Portuguese medical students [14, 24] concluded that empathy is positively associated with Agreeableness and Openness. Another study, which used IRI in Chinese medical students, found a strong association between Empathic Concern and Agreeableness, and Personal Distress with Neuroticism [23]. We have not found any study using the EQ in medical students. One study carried out with Psychology University students concluded that Agreeableness, Openness, Conscientiousness and Extraversion could be considered predictors of empathy as measured with the IRI [25]. A general population study found an association between IRI-PT and Openness and Agreeableness personality traits [26]. Another study with the general population found strong associations between the EQ with Agreeableness and Extraversion [27], but a study of Japanese university students found no association between the EQ and the NEO-FFI [28]. In a four-country multi-centre study of university students that correlated EQ and IRI, with NEO-FFI, the EQ had the highest correlation with Agreeableness, IRI-FS with Openness, and IRI-PD with Neuroticism [29].

Given the influence that personality can have on empathy, the aim of this research is to explore the relationship between empathy and personality, using three different measures of empathy and taking into account gender and specialty preference.

\section{Methods}

This observational cross-sectional study was conducted in a single institution, and the study population consisted of medical students. A description of the project, together with an invitation to participate and a link to access the online questionnaire were send by email from the Faculty of Medicine in Spain. The survey was administered in the 2016/2017 academic year. A total of 669 medical students ( $70.55 \%$ female) were enrolled during the 2016/2017 academic year. 110 medical students completed the survey. Participation was voluntarily with informed consent, and no incentives were offered. The response rate was the $16.44 \%$.

The study was approved by the ethics committee for clinical research (CEIC). The confidentiality was ensured. Only the principal investigator has an access to survey results. The data collected were used exclusively for the purpose of the study.

The online questionnaire included sociodemographic questions (age, gender and academic course) and the following self-report measurement instruments:

1. The JSPE consists of 20 items with scores ranging between 20 and 140. It measures empathy in the context of medical education [4]. The JSPE has been used in most of the studies carried out with medical students. In this study the adapted and validated Spanish version by Alcorta-Garza et al. [30] was used.

2. The IRI is formed by four subscales of seven items each with scores ranging from 0 to 28 . Two subscales measure cognitive empathy (IRI-PT and IRI-FS) and two subscales measure affective empathy (IRI-EC and IRI-PD) [6]. IRI-PT measures the spontaneous ability to adopt the perspective of others in real situations of daily life. IRI-FS measures the imaginative ability to put oneself in fictitious situations. IRI-EC measures compassion and concern feelings towards discomfort of others. IRI-PD measures anxiety and discomfort feelings in oneself when observing the negative experiences of others. In the present study, the Spanish validated version of Carrasco-Ortiz et al. [31] has been used.

3. The EQ consists of 60 items, 40 measure empathy and 20 measure control. Scores range from 0 to 80 . It measures cognitive and affective empathy in adults. EQ allows classification into four categories, which facilitates the comparison between groups. The cut off for each level is: from 0 to 32 scores is low empathy (average scores in Asperger Syndrome is 20), from 33 to 52 scores: average empathy (average in men 42 , average in women 47 ), from 53 to 63 scores: above average, from 64 to 80 scores high empathy. The version used, which has not been validated in Spanish, was obtained from http://espectroautista.info/EQ-es.html. We have the author's consent to use the EQ questionnaire [1].

5. Specialty preference classification is based on Hojat's study $[4,9]$ which defines two categories of professional preference: people-oriented specialties (Internal Medicine, Family Medicine, Pediatrics, Neurology, Rehabilitation, 
Psychiatry, Emergency Medicine, Obstetrics and Gynecology, Ophthalmology, Dermatology), and technology-oriented specialties (Surgery and Surgical Specialties, Radiology, Radiation Oncology, Pathology, Anesthesiology).

6. The NEO Five-Factor Inventory (NEO-FFI) is the short form version of one of the most prestigious instruments for the evaluation of normal personality [22]. The NEO-FFI consists of 60 items and evaluates five main factors. Openness to experience $(\mathrm{O})$, describes the trend to seek new personal experiences and to creatively conceive the future; Conscientiousness $(\mathrm{C})$ describes responsibility, ability to focus on goals, and discipline to carry them out; Extraversion (E) describes the trend to be open to others in social contexts; Agreeableness (A) describes kindness, respect and tolerance towards others; and Neuroticism $(\mathrm{N})$ describes emotional stability and how to deal with the problems of life. As well as the direct scores, the corresponding percentiles have been obtained based on scales from the Spanish population [32].

\section{Statistical methods}

Quantitative variables were described as means and standard deviations if they were normally distributed. For non-normally distributed quantitative variables, evaluated by the Shapiro-Wilks test, we used medians and interquartile ranges. Frequencies and percentages were used to describe the qualitative variables. Differences between the empathy scales by gender and specialty preference were analysed using the Student's t-test or the Mann-Whitney U test. Correlations between the empathy and personality variables were assessed by calculating the Spearman's rho. Multivariable linear regression analysis was performed to assess the association between personality traits (NEO-FFI dimensions) and empathy. We fitted different models for each empathy scale (JSPE, IRI-PT, IRI-FS, IRI-EC, IRI-PD and EQ). The explanatory variables were the NEO-FFI dimensions, adjusting by gender and specialty preference. The selection of variables was performed by backward stepwise regression, removing variables from the model by means of the $\mathrm{F}$ test. We explored all first order interactions between adjusting variables (gender and specialty preference) and the personality variables included in the model. The final models were assessed for residual validation. Goodness-of-fit was assessed by means of R-squared and adjusted R-squared.

All statistical tests were two-sided at a significance level of 0.05 . Statistical analysis was carried out with the $\mathrm{R}$ software. [33].

\section{Results}

Descriptive results of the study sample are shown in Table 1. Most of the medical students were women, from advanced courses, and had a people-oriented
Table 1 Descriptive analysis of the study sample

\begin{tabular}{|c|c|c|}
\hline \multicolumn{2}{|l|}{ Characteristic } & $N=110$ \\
\hline \multicolumn{2}{|l|}{ Age (years) } & $22.0(20.0-23.0)$ \\
\hline \multicolumn{2}{|l|}{ Gender (women) } & $84(76.4 \%)$ \\
\hline \multicolumn{3}{|l|}{ Academic year } \\
\hline \multicolumn{2}{|l|}{ (1st-2nd-3rd) } & $41(37.3 \%)$ \\
\hline \multicolumn{2}{|l|}{ (4th-5th-6th) } & $69(62.7 \%)$ \\
\hline \multicolumn{2}{|c|}{ Specialty preference (people-oriented) } & $80(72.7 \%)$ \\
\hline \multirow[t]{11}{*}{ Empathy } & JSPE & $120.5(111.2-129.8)$ \\
\hline & IRI-PT (Perspective Taking) & $18.3(3.9)$ \\
\hline & IRI-FS (Fantasy Scale) & $18.0(14.0-23.8)$ \\
\hline & IRI-EC (Empathic Concern) & $23.0(20.0-24.0)$ \\
\hline & IRI-PD (Personal Distress) & $8.0(5.0-11.0)$ \\
\hline & EQ (quantitative scale) & $49.0(41.2-57.0)$ \\
\hline & EQ (qualitative scale) & \\
\hline & Low (0-32) & $5(4.5 \%)$ \\
\hline & Average (33-52) & $61(55.5 \%)$ \\
\hline & Above average (53-63) & $36(32.7 \%)$ \\
\hline & High (64-80) & $8(7.3 \%)$ \\
\hline \multirow[t]{10}{*}{ Personality (NEO-FFI) } & Openness to experience $(\mathrm{O})$ & $32.1(6.9)$ \\
\hline & Conscientiousness (C) & $31.6(7.9)$ \\
\hline & Extraversion (E) & $31.7(7.0)$ \\
\hline & Agreeableness (A) & $30.8(7.1)$ \\
\hline & Neuroticism (N) & $23.0(8.6)$ \\
\hline & Percentile $\mathrm{O}$ & $75.0(60.0-95.0)$ \\
\hline & Percentile C & $40.0(20.0-70.0)$ \\
\hline & Percentile E & $55.0(40.0-85.0)$ \\
\hline & Percentile A & $25.0(11.2-53.8)$ \\
\hline & Percentile N & $55.0(25.0-75.0)$ \\
\hline
\end{tabular}

Quantitative variables are presented as median and interquartile range, or mean and standard deviation; qualitative variables are presented as number and percentage

JSPE Jefferson Scale of Physician Empathy, IRI Interpersonal Reactivity Index, EQ Empathy Quotient, NEO-FFI NEO Five-Factor Inventory

specialty preference. The percentile scores for Agreeableness recorded by our students were below those recorded for the Spanish population [32], while those for Openness to experience were higher. Women recorded a higher IRI-EC score $(p=0.026)$. Students with people-oriented specialty preference recorded higher levels of the JSPE ( $p$ $=0.009)$ and the IRI-PD $(p=0.006)$ (Additional file 1 : Table S1).

The empathy scales showed weak and moderate correlation with all the personality traits (Table 2). The strongest correlations were observed between IRI-FS and Openness, Spearman's rho (95\% confidence interval) of $0.465(0.305,0.600)$; and between IRI-PD and Neuroticism, $0.438(0.273,0.578)$. Medical students with below average EQ scores recorded low scores for Openness to experience, Conscientiousness, Extraversion and 
Table 2 Correlations between empathy and personality variables

\begin{tabular}{lccccc}
\hline & $\mathrm{O}$ & $\mathrm{C}$ & $\mathrm{E}$ & $\mathrm{A}$ & $\mathrm{N}$ \\
\hline JSPE & $0.337(0.160,0.493)$ & $0.088(-0.101,0.270)$ & $0.249(0.064,0.416)$ & $0.357(0.182,0.510)$ & $-0.086(-0.269,0.103)$ \\
& $<0.001$ & 0.363 & 0.009 & $<0.001$ & 0.372 \\
IRI-PT & $0.299(0.119,0.461)$ & $0.179(-0.009,0.354)$ & $0.005(-0.183,0.192)$ & $0.220(0.034,0.391)$ & $-0.130(-0.310,0.058)$ \\
& 0.001 & 0.062 & 0.960 & 0.021 & 0.174 \\
IRI-FS & $0.465(0.305,0.600)$ & $-0.157(-0.335,0.031)$ & $0.208(0.021,0.380)$ & $0.047(-0.142,0.232)$ & $0.135(-0.054,0.314)$ \\
& $<0.001$ & 0.101 & 0.029 & 0.629 & 0.161 \\
IRI-EC & $0.224(0.039,0.395)$ & $0.049(-0.140,0.234)$ & $0.288(0.106,0.451)$ & $0.307(0.127,0.467)$ & $0.172(-0.016,0.348)$ \\
& 0.019 & 0.614 & 0.002 & 0.001 & 0.072 \\
IRI-PD & $-0.009(-0.195,0.179)$ & $-0.103(-0.285,0.086)$ & $-0.224(-0.395,-0.038)$ & $-0.100(-0.282,0.089)$ & $0.438(0.273,0.578)$ \\
& 0.929 & 0.285 & 0.019 & 0.298 & $<0.001$ \\
EQ & $0.344(0.167,0.499)$ & $0.238(0.053,0.407)$ & $0.373(0.200,0.524)$ & $0.383(0.210,0.532)$ & $-0.114(-0.295,0.075)$ \\
& $<0.001$ & 0.012 & $<0.001$ & $<0.001$ & 0.235 \\
\hline
\end{tabular}

Spearman's rho ( $95 \%$ confidence interval), $p$-value

O Openness to experience, C Conscientiousness, E Extraversion, A Agreeableness, N Neuroticism, JSPE Jefferson Scale of Physician Empathy, IRI Interpersonal Reactivity Index, PT Perspective Taking, FS Fantasy Scale, EC Empathic Concern, PD Personal Distress, EQ Empathy Quotient

Agreeableness, and high scores for Neuroticism. When comparing the extreme groups (low EQ vs high EQ), significant differences were observed for almost all personality traits (Additional file 1: Table S2).

Table 3 shows results of multivariable analysis for each empathy scale. In addition to specialty preference, the JSPE was associated significantly with Openness personality trait, while a higher JSPE score was associated with higher Agreeableness only in students with technology-oriented specialty preference (Fig. 1a). IRI-PT was significantly associated with all dimensions of NEO-FFI. Higher IRI-PT scores were associated with higher Agreeableness, Openness and Conscientiousness, and low Extraversion and Neuroticism scores. Regardless of gender and specialty preference, IRI-FS was associated with Openness personality trait, with higher effect among men (Fig. 1b). Higher IRI-FS was associated with lower Conscientiousness (Fig. 1c) and lower Extraversion only among men (Fig. 1d). IRI-EC was significantly associated with Extraversion, Agreeableness and Neuroticism scores. IRI-PD was only associated with Neuroticism, furthermore to specialty preference with lower IRI-PD scores for students with technology-oriented specialty preference. The EQ score was significantly associated with Openness, Conscientiousness and Extraversion, while a higher EQ score was associated with higher Agreeableness score in students with technology-oriented specialty preference (Fig. 1e). Big five personality traits, taken into account gender and specialty preference, explained $24-43 \%$ of variance of the empathy scores.

\section{Discussion}

This study explores the relationship between three empathy scales and the Big Five personality traits in medical students, taking into account gender and specialty preference, not yet been explored in previous studies.
In our sample, there were no gender differences in the JSPE medical empathy scale as in other studies [11] nor in the EQ. However, higher IRI-EC values were observed among women, as already Neumann et al. [7] observed. Female superiority in this ability according to the evolutionary theory of gender might explain these results [34].

In medical students with people-oriented specialty preference, a higher score was observed in the JSPE and IRI-PD, as found in previous studies $[4,9,11,13,16,19]$. The JSPE specifically evaluates empathy in the medical context, the focus of attention being the patient. In some technology oriented specialties empathy maybe is less apparent or important in the doctor-patient relationship [4, 9]. IRI-PD evaluates anxiety and discomfort feelings when observing the patients' suffering and discomfort. Therefore, learning to manage anxiety could improve social relationships and empathic behaviour [35].

Regarding the Big Five personality model, the Openness to experience percentile of medical students was higher and the Agreeableness lower than those in the Spanish population. Neuroticism, Extraversion and Conscientiousness percentiles were similar [32]. Although Agreeableness implies tolerance and respect for others, lower Agreeableness score reflects more scepticism and competitiveness, which may be requisite traits in science.

In our sample, JSPE was positively associated with Openness, and with Agreeableness only in students with technology-oriented specialty preference. These results are similar to previous studies in Portuguese medical students [14, 24].

IRI-PT was positively associated with Agreeableness, Openness and Conscientiousness, and negatively with Extraversion and Neuroticism. The recent study in Chinese medical students show similar results except Extraversion [23].

IRI-FS was positively associated with Openness, and negatively with Conscientiousness and Extraversion, 
Table 3 Multivariable linear regression analysis between empathy and personality, adjusted by gender and specialty preference

\begin{tabular}{|c|c|c|c|c|c|}
\hline & & Beta & SE & $p$-value & Multiple $\mathrm{R}^{2}$ \\
\hline \multirow[t]{6}{*}{ JSPE } & Constant & 98.50 & 6.42 & $<0.001$ & 0.366 \\
\hline & Men & -0.24 & 2.18 & 0.914 & \\
\hline & Technology-oriented & -32.05 & 8.53 & $<0.001$ & \\
\hline & O & 0.47 & 0.14 & 0.001 & \\
\hline & A & 0.26 & 0.16 & 0.110 & \\
\hline & Technology-oriented*A & 0.86 & 0.27 & 0.002 & \\
\hline \multirow[t]{8}{*}{ IRI-PT } & Constant & 9.57 & 3.01 & 0.002 & 0.287 \\
\hline & Men & -0.50 & 0.81 & 0.542 & \\
\hline & Technology-oriented & 0.02 & 0.75 & 0.977 & \\
\hline & O & 0.24 & 0.05 & $<0.001$ & \\
\hline & c & 0.12 & 0.04 & 0.005 & \\
\hline & E & -0.12 & 0.06 & 0.031 & \\
\hline & A & 0.12 & 0.05 & 0.015 & \\
\hline & N & -0.12 & 0.04 & 0.009 & \\
\hline \multirow[t]{9}{*}{ IRI-FS } & Constant & 6.49 & 4.07 & 0.114 & 0.372 \\
\hline & Men & 13.56 & 8.23 & 0.102 & \\
\hline & Technology-oriented & -0.70 & 1.08 & 0.520 & \\
\hline & O & 0.28 & 0.09 & 0.003 & \\
\hline & C & -0.03 & 0.07 & 0.707 & \\
\hline & E & 0.13 & 0.08 & 0.116 & \\
\hline & Men*O & 0.33 & 0.15 & 0.033 & \\
\hline & $\mathrm{Men}^{*} \mathrm{C}$ & -0.34 & 0.15 & 0.024 & \\
\hline & Men*E & -0.50 & 0.18 & 0.005 & \\
\hline \multirow[t]{6}{*}{ IRI-EC } & Constant & 8.99 & 2.76 & 0.002 & 0.242 \\
\hline & Men & -1.41 & 0.86 & 0.106 & \\
\hline & Technology-oriented & 0.13 & 0.81 & 0.870 & \\
\hline & E & 0.12 & 0.06 & 0.046 & \\
\hline & A & 0.23 & 0.05 & $<0.001$ & \\
\hline & N & 0.10 & 0.05 & 0.038 & \\
\hline \multirow[t]{4}{*}{ IRI-PD } & Constant & 1.90 & 1.18 & 0.111 & 0.326 \\
\hline & Men & 0.54 & 0.92 & 0.563 & \\
\hline & Technology-oriented & -2.17 & 0.87 & 0.014 & \\
\hline & N & 0.30 & 0.05 & $<0.001$ & \\
\hline \multirow[t]{8}{*}{ EQ } & Constant & 11.96 & 6.45 & 0.067 & 0.431 \\
\hline & Men & -0.63 & 1.83 & 0.733 & \\
\hline & Technology-oriented & -22.93 & 7.07 & 0.002 & \\
\hline & O & 0.43 & 0.12 & $<0.001$ & \\
\hline & C & 0.34 & 0.10 & 0.001 & \\
\hline & E & 0.31 & 0.12 & 0.010 & \\
\hline & A & 0.10 & 0.14 & 0.448 & \\
\hline & Technology-oriented*A & 0.69 & 0.23 & 0.003 & \\
\hline
\end{tabular}

SE standard error, $O$ Openness to experience, $C$ Conscientiousness, $E$ Extraversion, A, Agreeableness, N Neuroticism, JSPE Jefferson Scale of Physician Empathy, IRI Interpersonal Reactivity Index, PT Perspective Taking, FS Fantasy Scale, EC Empathic Concern, PD Personal Distress, EQ Empathy Quotient

* stands for interaction term similar to Melchers' results [29]. We observed a higher effect among men in these associations. In our opinion, probably an open and more flexible attitude fosters fantasy, imagination and creativity.

IRI-EC was positively associated with Extraversion, Agreeableness and Neuroticism. Song \& Shi [23] report similar results except in Extraversion. Cultural differences in Chinese population could explain mixed results in Extraversion [36].

IRI-PD was only positively associated with Neuroticism, as found in other studies [23, 29]. Technology-oriented specialty preference was associated with a decrease of IRI-PD. The relationship with anxiety and the possibility of improving it could be one of the main goals of personalized interventions [37].

Song's study does not use IRI-FS, as some authors considered subscales IRI-PT and IRI-EC relevant for patient care, underestimating IRI-FS and IRI-PD [19, 38, 39]. We think that neither IRI-FS nor IRI-PD can be dismissed, since they provide relevant information as to how the student approaches the doctor-patient relationship [35].

We have not found previous studies, to compare the results, with the EQ in medical students. Medical students with below average EQ scores recorded low scores for Openness. However, we found EQ was positively associated with Openness, Conscientiousness and Extraversion, and associated with Agreeableness in students with technology-oriented specialty preference. These results partial match with those of Melchers' and collaborators [29]. We highlight that some students who prefer more technological specialties are those who had the highest Agreeableness scores. Students with extreme empathy scores (low and high) showed a differential personality pattern; those with high empathy sometimes could avoid people-oriented specialties to not get emotionally involved and not increase the basal anxiety. Those with low empathy were more introverted, anxious and they had a less open attitude.

Gender and specialty preference could modify the relationship between empathy and personality. Thus gender and specialty preference are variables that should be taken into account in empathy research in medical students. The explanatory and predictive capacity of this relationship is limited, supporting the consideration of empathy as a complex multidimensional socio-emotional competency $[40,41]$.

The results obtained with the three empathy scales can help to decide the empathy model to be used to develop personalized empathy interventions. The JSPE would be specific to evaluate medical empathy. Multidimensional model of the IRI allows study of both affective and cognitive empathy, and the EQ allows identifying extreme empathy scores. Probably, personality could be a good predictor in vulnerable medical students 

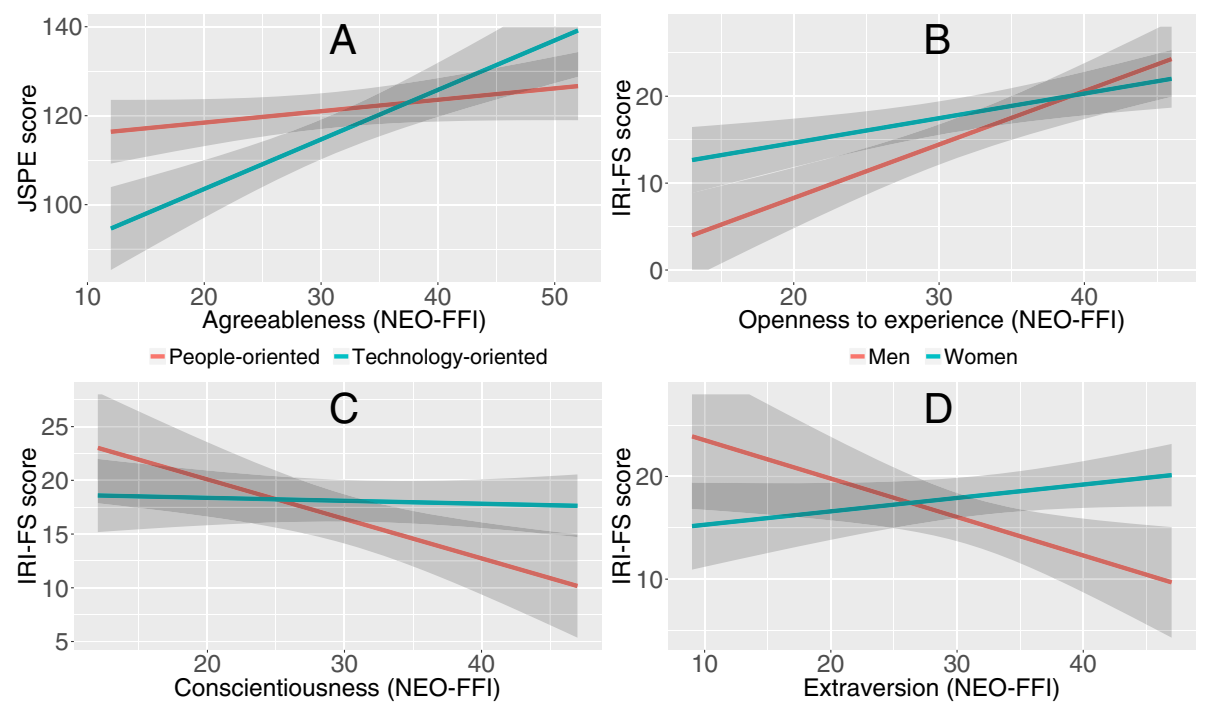

- Men - Women

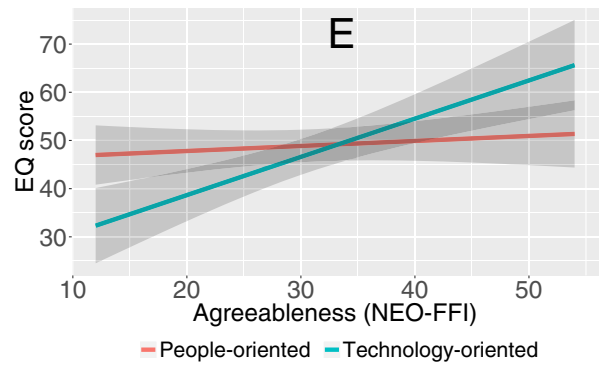

Fig. 1 Interactions of gender or specialty preference with personality traits from multivariable models for empathy scales. a: Model for JSPE score: interaction between Agreeableness and specialty preference; $\mathbf{b}$ : Model for IRI-FS score: interaction between Openness to experience and gender; c: Model for IRI-FS score: interaction between Conscientiousness and gender; $\mathbf{d}$ : Model for IRI-FS score: interaction between Extraversion and gender; e: Model for EQ score: interaction between Agreeableness and specialty preference. JSPE, Jefferson Scale of Physician Empathy; IRI, Interpersonal Reactivity Index; FS, Fantasy Scale; EQ, Empathy Quotient

with extreme scores of empathy who benefit most from a specialty choice advice [35].

Given the differentiation between affective and cognitive empathy and that some dimensions of empathy can, perhaps, be taught and modified, these results may help to design programs to study the effects of personalized intervention strategies [23]. The results of two pilot studies recently published by our team show the wide acceptance of two psychoeducational intervention (sensory deprivation and shadowing patients) easily implemented in undergraduate medical studies [42, 43]. Accordingly, we proposed to improve cognitive empathy by increasing attitudes related to the agreeableness trait. People with low agreeableness may have difficulty focusing their attention on others, hence, we propose to train perspective taking in a fictional context with intervention strategies that will help them to direct the focus of attention towards the other patients, without fear or defensive behaviours that will distance them from patients. We also propose to improve affective empathy by modulating neuroticism and anxiety related to empathic concern and personal distress, especially in students with people-oriented specialty preference, who tend to have higher anxiety in their relationship with patients. According to our results, we might teach medical students to accurately perceive and identify their emotions and those of others. Although they could improve the scores of Agreeableness and decrease Neuroticism scores, above all it would improve empathic behaviour and patient care.

This study has different limitations. This observational cross-sectional study was conducted in a single institution. Although the sample of 110 medical students may not be representative of the general medical student population, it opens empathy research lines to be evaluated in future multi-centre studies. Our students were participating in another study at the same time, and their collaboration was not always easy.

Our study provides new perspectives in psychoeducational interventions to advise and improve empathy in medical students with extreme values. Although we have experience in both individualized and group interventions, we are aware of the need for future methodologically 
better-supported studies to verify or confirm that personalized intervention strategies could improve empathy in medical students.

We used self-report instruments that inform us of the perception that the individual has of himself and of his abilities. Our team is interested in simplifying and optimizing the correlation process of psychometric instruments traditionally used, and new biometric devices that provide more objective information about emotions [44].

The low proportion of males was a limitation of our study but reflects the increased proportion of women attending medical school; 70\% in Spain [45], and is similar to gender in our Faculty.

In the Big Five model, NEO-FFI-R structure analyses show only a slight improvement in Openness and Agreeableness reliability, but correlations between the five dimensions of the NEO-FFI and the NEO-FFI-R are similar to each other, and they correspond to those expected. The choice of one or the other depends on the necessity to compare results with other studies [46]. For this reason, in this study we chose the NEO-FFI to be able to compare our results with the version used in previous studies of personality in medical students [14, 23, 24].

\section{Conclusions}

This study confirmed that the empathy is related to personality. Gender and specialty preference can modify this relationship. Using three different measures of empathy allows personalizing the evaluation of the different empathy models of empathy and its relation with personality traits. The strongest correlations were observed between IRI-Fantasy Scale and Openness to experience, and between IRI-Personal Distress and Neuroticism. These results can help to design programs to study whether some personalized intervention strategies could improve the empathy in medical students by increasing perspective taking ability and decreasing anxiety. However, more studies are needed to verify these hypotheses. Although they could improve the scores of Agreeableness and decrease Neuroticism scores, above all it would improve empathic behaviour and patient care.

\section{Additional file}

Additional file 1: Table S1. Differences between empathy scales by gender and specialty preference. Variables are described with medians and interquartile ranges, except for IRI-PT that is described with mean and standard deviation. JSPE, Jefferson Scale of Physician Empathy; IRI, Interpersonal Reactivity Index; PT, Perspective Taking; FS, Fantasy Scale; EC, Empathic Concern; PD, Personal Distress; EQ, Empathy Quotient. a. Mann-Whitney $U$ test, except for IRI-TP that is analysed with the t test. Table S2. Bivariate analysis between Empathy Quotient (qualitative scale) and personality. Variables are presented as median and interquartile range, or mean and standard deviation. P-values correspond to the Mann-Whitney $U$ test or the t-test comparing the extreme groups: low Empathy Quotient score vs high Empathy Quotient score. (DOCX 16 kb)

\section{Abbreviations}

A: Agreeableness; C: Conscientiousness; E: Extraversion; EQ: Empathy Quotient; IRI: Interpersonal Reactivity Index; IRI-EC: Interpersonal Reactivity Index-Subscale Empathetic Concern; IRI-FS: Interpersonal Reactivity IndexSubscale Fantasy Scale; IRI-PD: Interpersonal Reactivity Index- Subscale Personal Distress; IRI-PT: Interpersonal Reactivity Index-Subscale Perspective Taking; JSPE: Jefferson Scale of Physician Empathy; N: Neuroticism; NEO-

FFI: NEO Five-Factor Inventory; O: Openness to experience

\section{Acknowledgements}

The authors are deeply grateful for collaboration from medical students of University of Lleida. We thank Sofia Rotger-Della for their helpful review of the manuscript

\section{Funding}

The authors report no external funding source for this study.

\section{Availability of data and materials}

Data sharing is not applicable to this article as no datasets were generated or analysed during the current study. The identifying/confidential patient data should not be shared.

\section{Authors' contributions}

All authors have made substantial contributions to the work reported. TG, IB, JSG contributed to the study design, recruitment and data collection; $T G$, IB, JSG, CF contributed to analysis of data, interpretation of results, writing of the manuscrit. All authors read and approved the final manuscript.

\section{Ethics approval and consent to participate}

The study was carried out according to the principles of the declaration of Helsinki, and approved by the Ethics Committee on Clinical Research of the Arnau de Vilanova University Hospital in Lleida (Spain) CEIC-1515.

We obtained written consent from subjects prior to participation in the study.

\section{Consent for publication}

Not applicable.

\section{Competing interests}

The authors declare that they have no competing interests.

\section{Publisher's Note}

Springer Nature remains neutral with regard to jurisdictional claims in published maps and institutional affiliations.

\section{Author details}

${ }^{1}$ Psychiatry Service, Santa Maria University Hospital, Rovira Roure Avenue, 44, 25198 Lleida, Spain. ${ }^{2}$ Institute for Biomedical research in Lleida Dr. Pifarré Foundation (IRBLleida), Lleida, Spain. ${ }^{3}$ Department of Medicine, Faculty of Medicine, University of Lleida, Lleida, Spain. ${ }^{4}$ Department of Basic Medical Sciences, University of Lleida, Lleida, Spain. ${ }^{5}$ Biostatistics Unit, Institute for Biomedical Research in Lleida Dr. Pifarré Foundation (IRBLleida), Lleida, Spain.

Received: 29 June 2018 Accepted: 4 February 2019

Published online: 14 February 2019

\section{References}

1. Baron-Cohen S, Wheelwright $\mathrm{S}$. The empathy quotient: an investigation of adults with Asperger syndrome or high functioning autism, and normal sex differences. J Autism Dev Disord. 2004;34(2):163-75.

2. Guilera LT. Empathy. Conceptualization and neurobiological bases. Empatía. Conceptualización y bases neurobiológicas. An Psiquiatr. 2008;24(5):216-22.

3. Sulzer SH, Feinstein NW, Wendland CL. Assessing empathy development in medical education: a systematic review. Med Educ. 2016;50(3):300-10.

4. Hojat M, Gonnella JS, Nasca TJ, Mangione S, Vergare M, Magee M. Physician empathy: definition, components, measurement, and relationship to gender and specialty. Am J Psychiatry. 2002;159(9):1563-9.

5. Hojat M, Gonnella JS. Eleven years of data on the Jefferson scale of empathy-medical student version (JSE-S): proxy norm data and tentative cutoff scores. Med Princ Pract. 2015;24(4):344-50. 
6. Davis $\mathrm{MH}$. Measuring individual differences in empathy: evidence for a multidimensional approach. J Pers Soc Psychol. 1983;44(1):113-26.

7. Neumann M, Scheffer C, Tauschel D, Lutz G, Wirtz M, Edelhäuser F. Physician empathy: definition, outcome-relevance and its measurement in patient care and medical education. GMS Z Med Ausbild. 2012;29(1):Doc11.

8. Baron-Cohen S, Richler J, Bisarya D, Gurunathan N, Wheelwright S. The systemizing quotient: an investigation of adults with Asperger syndrome or highfunctioning autism, and normal sex differences. B Biol Sci. 2003;358(1430):361-74.

9. Chen D, Lew R, Hershman W, Orlander J. A cross-sectional measurement of medical student empathy. J Gen Intern Med. 2007;22(10):1434-8.

10. Chen DCR, Kirshenbaum DS, Yan J, Kirshenbaum E, Aseltine RH Characterizing changes in student empathy throughout medical school. Med Teach. 2012;34(4):305-11.

11. Di Lillo M, Cicchetti A, Lo SA, Taroni F, Hojat M. The Jefferson scale of physician empathy: preliminary psychometrics and group comparisons in Italian physicians. Acad Med. 2009;84(9):1198-202.

12. Kataoka HU, Koide N, Hojat M, Gonnella JS. Measurement and correlates of empathy among female Japanese physicians. BMC Med Educ. 2012;12(1):48.

13. Tavakol S, Dennick R, Tavakol M. Psychometric properties and confirmatory factor analysis of the Jefferson scale of physician empathy. BMC Med Educ. 2011;11(1):54.

14. Magalhães E, Costa P, Costa MJ. Empathy of medical students and personality: evidence from the five-factor model. Med Teach. 2012;34(10):807-12.

15. Quince TA, Parker RA, Wood DF, Benson JA. Stability of empathy among undergraduate medical students: a longitudinal study at one UK medical school. BMC Med Educ. 2011;11(1):90.

16. Suh DH, Hong JS, Lee DH, Gonnella JS, Hojat M. The Jefferson scale of physician empathy: a preliminary psychometric study and group comparisons in Korean physicians. Med Teach. 2012;34(6):e464-8.

17. Hasan S, Al-Sharqawi N, Dashti F, AbdulAziz M, Abdullah A, Shukkur M, et al. Level of empathy among medical students in Kuwait University, Kuwait. Med Princ Pract. 2013;22(4):385-9.

18. Hegazi I, Wilson I. Maintaining empathy in medical school: it is possible. Med Teach. 2013:35(12):1002-8.

19. Hojat M. Ten approaches for enhancing empathy in health and human services cultures. J Health Hum Serv Adm. 2009 Spring:31(4):412-50.

20. Esquerda M, Yuguero O, Viñas J, Pifarré J. La empatía médica, ¿nace o se hace? Evolución de la empatía en estudiantes de medicina. Atención Primaria. 2016:48(1):8-14

21. McManus I, Keeling A, Paice E. Stress, burnout and doctors' attitudes to work are determined by personality and learning style: a twelve year longitudinal study of UK medical graduates. BMC Med. 2004;2(1):29.

22. Costa PT, McCrae RR. Normal personality assessment in clinical practice: the NEO personality inventory. Psychol Assess. 1992;4(1):5-13.

23. Song $Y$, Shi M. Associations between empathy and big five personality traits among Chinese undergraduate medical students. PLoS One. 2017;12(2): e0171665.

24. Costa P, Alves R, Neto I, Marvão P, Portela M, Costa MJ. Associations between medical student empathy and personality: a multi-institutional study. PLoS One. 2014;9(3):e89254.

25. lacovella JD, Díaz-Lázaro CM, Richard's MM. Relación entre la empatía y los cinco grandes factores de personalidad en una muestra de estudiantes. Rev Argent Cienc Comport. 2015;1:14-21.

26. Schaefer $M$, Rotte $M$, Heinze H-J, Denke C. Mirror-like brain responses to observed touch and personality dimensions. Front Hum Neurosci. 2013;7:227.

27. Nettle D. Empathizing and systemizing: what are they, and what do they contribute to our understanding of psychological sex differences? $\mathrm{Br} J$ Psychol. 2007;98(2):237-55.

28. Wakabayashi A, Kawashima H. Is empathizing in the E-S theory similar to agreeableness? The relationship between the EQ and SQ and major personality domains. Pers Individ Dif. 2015;76:88-93.

29. Melchers MC, Li M, Haas BW, Reuter M, Bischoff L, Montag C. Similar personality patterns are associated with empathy in four different countries. Front Psychol. 2016;7:290.

30. Alcorta-Garza A, González-Guerrero JF, Tavitas-Herrera SE, Rodríguez-Lara FJ, Hojat M. Validación de la Escala de Empatía Médica de Jefferson en estudiantes de medicina mexicanos. Salud Mental. 2005;28(5):57-63.

31. Carrasco-Ortiz MA, Delgado-Egido B, Barbero-García MI, Holgado-Tello FP, Del Barrio-Gándara MV. Propiedades psicométricas del Interpersonal Reactivity Index (IRI) en población infantil y adolescente española. Psicothema. 2011. 23(4):824-31.
32. Costa PT, McCrae RR. Inventario de Personalidad NEO Revisado (NEO PI-R) e Inventario NEO Reducido de Cinco Factores (NEO FFI). Madrid: TEA; 1999.

33. R Core Team. R: A language and environment for statistical computing. $\mathrm{R}$ Foundation for Statistical Computing; Viena, Austria. 2018. https://www.rproject.org/.

34. Trofimova I. Do psychological sex differences reflect evolutionary bisexual partitioning? Am J Psychol. 2015;128(4):485-514.

35. Guilera T, Batalla I, Soler-González J. Article in press. Empathy and specialty preference in medical students. Follow-up study and feedback. Educ Med. 2017; Available from: https://doi.org/10.1016/j.edumed.2017.07.017.

36. Yang KS. Chinese personality and its change. In: Bond MH, editor. The psychology of the Chinese people. Oxford: Oxford University Press; 1986. p. 106-70.

37. Yusoff MSB. Interventions on medical students' psychological health: a meta-analysis. J Taibah Univ Med Sci. 2014:9(1):1-13.

38. Costa P, de Carvalho-Filho MA, Schweller M, Thiemann P, Salgueira A, Benson J, et al. Measuring medical students' empathy. Acad Med. 2017; 92(6):860-7.

39. Quince T, Thiemann P, Benson J, Hyde S. Undergraduate medical students' empathy: current perspectives. Adv Med Educ Pract. 2016;7:443-55.

40. Mooradian TA, Davis M, Matzler K. Dispositional empathy and the hierarchical structure of personality. Am J Psychol. 2011;124(1):99-109.

41. Gleichgerrcht $E$, Decety J. Empathy in clinical practice: how individual dispositions, gender, and experience moderate empathic concern, burnout, and emotional distress in physicians. PLoS One. 2013;8(4):e61526.

42. Guilera T, Batalla I, Soler-González J. Experiencing empathy in medical students: sensorial deprivation. Experimentar empatía en estudiantes de medicina: deprivación sensorial. FEM. 2017;20(2):53-5.

43. Guilera T, Batalla I, Soler-González J. Sehadowing patients: experiencing empathy in medical students. Shadowing patients: experimentar empatía en estudiantes de medicina. Educ Med. Press, corrected proof, available online 15 de Setembre 2018; https://doi.org/10.1016/j.edumed.2018.06.006.

44. López-Gil J-M, Virgili-Gomá J, Gil R, Guilera T, Batalla I, Soler-González J, García R. Method for improving EEG based emotion recognition by combining it with synchronized biometric and eye tracking technologies in a non-invasive and low cost way. Front Comput Neurosci. 2016;10.

45. Arrizabalaga $\mathrm{P}$, Abellana $\mathrm{R}$, Viñas $\mathrm{O}$, Merino A, Ascaso C. Women doctors and their careers in a large university hospital in Spain at the beginning of the 21st century. Hum Resour Health. 2015;13:15.

46. Aluja A, Blanch A, Solé D, Dolcet JM, Gallart S. Versiones cortas del NEO-PI-R: el NEO-FFI frente al NEOFFI-R. Shortened versions of the NEO-PI-R: the NEOFFI versus the NEO-FFI-R. Behav Psychol. 2009;335-50.

\section{Ready to submit your research? Choose BMC and benefit from:}

- fast, convenient online submission

- thorough peer review by experienced researchers in your field

- rapid publication on acceptance

- support for research data, including large and complex data types

- gold Open Access which fosters wider collaboration and increased citations

- maximum visibility for your research: over $100 \mathrm{M}$ website views per year

At BMC, research is always in progress.

Learn more biomedcentral.com/submissions 